\title{
Surface of the filarial parasite Setaria digitata and the structural changes on treatment with Triton $\mathrm{X}-\mathbf{1 0 0}$
}

\author{
M. G. MADATHIPARAMBIL ${ }^{1}$, N. K. KAVITHA RAJ ${ }^{2}$, J. LINDA ${ }^{3}$, R. KALEYSA RAJ ${ }^{3 *}$
}

\begin{abstract}
${ }^{1}$ Regional Medical Research Centre (ICMR), Port Blair 744 101, Andaman and Nicobar Islands, India; ${ }^{2}$ Noorul Islam College of Dental Science, Nice Garden, Aralumoodu PO, Neyyatinkara, Kerala, India; ${ }^{3}$ Department of Biochemistry, University of Kerala, Kariavattom, Thiruvananthapuram - 695581, India, E-mail: kaleysaraj@yahoo.com
\end{abstract}

\begin{abstract}
Summary
Setaria digitata, a bovine filarial parasite is used as a laboratory model for filariasis. The studies showed that considerable amount of biochemically and immunologically active materials are present on the surface of the parasite. The effect of Triton X-100 on the surface of the parasite, when it is used to separate the surface associated materials, is not known. Treatment with Triton X-100 enhances the amount of ES protein released into the medium. The electron microscopic study of $S$. digitata wall showed that structure of the surface is similar to that of $W$. bancrofti. There are striations, annulations and button like bosses on the filarial surface. On treatment with Triton X-100 the electron dense cloudy layer on the surface was disappeared. The surface appeared to be suitable for hosting secreted molecules on the surface.
\end{abstract}

Keywords: filariasis; Setaria; surface structure; Triton X100; electron microscopy

\section{Introduction}

Setaria digitata (von Linstow) is a filarial parasite inhabiting the peritoneal cavity of the cattle (Bos indicus). General features of the parasite had been reviewed by Sheng (1959). The species $S$. digitata closely resembles to Setaria cervi. Comparison of the two species was also studied by Sheng (1958). Ever since the Setaria has been recommended as a model system for filariasis (Hawking, 1978) lot of studies have been carried out on the biochemical and immunological aspects of these parasites with a view to develop effective drugs against filariasis, for understanding the strategy of long survival of filarial parasites within the host and for developing effective diagnostic reagents.

$S$. digitata is a round ivory coloured with smooth cuticle and has a length of $65-75 \mathrm{~mm}$ and breadth of 0.5 to 0.7 $\mathrm{mm}$ for females and $35-45 \mathrm{~mm}$ and 0.2 to $0.3 \mathrm{~mm}$ respec- tively for males. The oesophagus is $6-7 \mathrm{~mm}$ long, the anterior part measuring 0.5 to $0.6 \mathrm{~mm}$ and the posterior part 5.5 to $6.5 \mathrm{~mm}$. At the tail end there is a terminal spherical knob that may be perfectly smooth or slightly rough with a papillated surface. The lateral caudal appendages are well developed (Sheng, 1959). The anatomical structure of the parasite has been further studied by Decruse and Kaleysa Raj (1990). This study carried out by histological methods revealed that the cuticle is a four layered structure with thick and unstained outer layer followed by intensely stained and faintly stained middle layers and intensely stained basement layer. Multilayer structures have been reported in the case of $S$. cervi (Kagai, 1960 a, b) and Litomosoides carinii (Kagai, 1963).

There are number of reports regarding release of ES materials. ES includes excretory, secretory as well as embryonic which are materials released during the release of microfilariae (Murugan \& Kaleysa Raj, 1991; Dhas \& Raj, 1995). Secretory materials form an important group of ES materials which play strategic role in the survival of the parasite (Bright \& Kaleysa Raj, 1990, 1991, 1992; Sugunan \& Raj, 1990; Devi \& Raj, 1996). A recent study carried out using the excretory secretory materials released from the $S$. digitata resulted in the isolation of a glycoprotein with molecular weight $200 \mathrm{kDa}$ (gp 200), useful for the diagnosis of filariasis (Madathiparambil et al., 2009). The immunolocalization study clearly showed that the 200 $\mathrm{kDa}$ protein is secreted out through the pores on the surface of both male and female parasites.

The Triton X-100 solubilises surface molecules of the parasite. Our earlier studies on protein extracted using Triton X-100 revealed the presence of immunologically active molecules on the surface of the filarial parasite $S$. digitata (John \& Raj, 1998; Muthian et al., 2006). The exact mechanism of secretion of secretory materials is still not clear. These need a study on the structure of the filarial wall. We have treated the parasite $S$. digitata with Triton 
Table 1. The release of proteins in to the incubation medium by the parasites in presence of Triton X-100

\begin{tabular}{ccccc}
\hline \multicolumn{2}{c}{$\begin{array}{c}\text { Treatment with Triton X-100 } \\
\text { at } 37^{\circ} \mathrm{C} \text { for } 10 \mathrm{~min}\end{array}$} & $\begin{array}{c}\text { Recovery after removal of Triton X-100 } \\
\text { at } 37^{\circ} \mathrm{C}\end{array}$ \\
\hline $\begin{array}{c}\text { Concentration } \\
\text { of Triton X-100 (\%) }\end{array}$ & $\begin{array}{c}\text { Released Protein } \\
\mu \mathrm{g} / \mathrm{g} \text { of worm }\end{array}$ & $\begin{array}{c}\text { Movement } \\
\text { of worm }\end{array}$ & $\begin{array}{c}\text { Time required } \\
\text { for recovery }\end{array}$ & $\begin{array}{c}\text { Movement } \\
\text { after recovery }\end{array}$ \\
\hline 0 & $40 \pm 0.9$ & Normal & $5 \mathrm{sec}$ & Normal \\
0.1 & $66 \pm 2.4$ & Paralyzed & $30 \mathrm{~min}-1 \mathrm{hr}$ & $\begin{array}{c}\text { Sluggish } \\
0.5\end{array}$ \\
$85 \pm 1.4$ & Paralyzed & $30 \mathrm{~min}-4 \mathrm{hrs}$ & $\begin{array}{c}\text { Sluggish } \\
\text { Non recovery in } 6 \mathrm{hrs}\end{array}$ & Worm dead \\
\hline
\end{tabular}
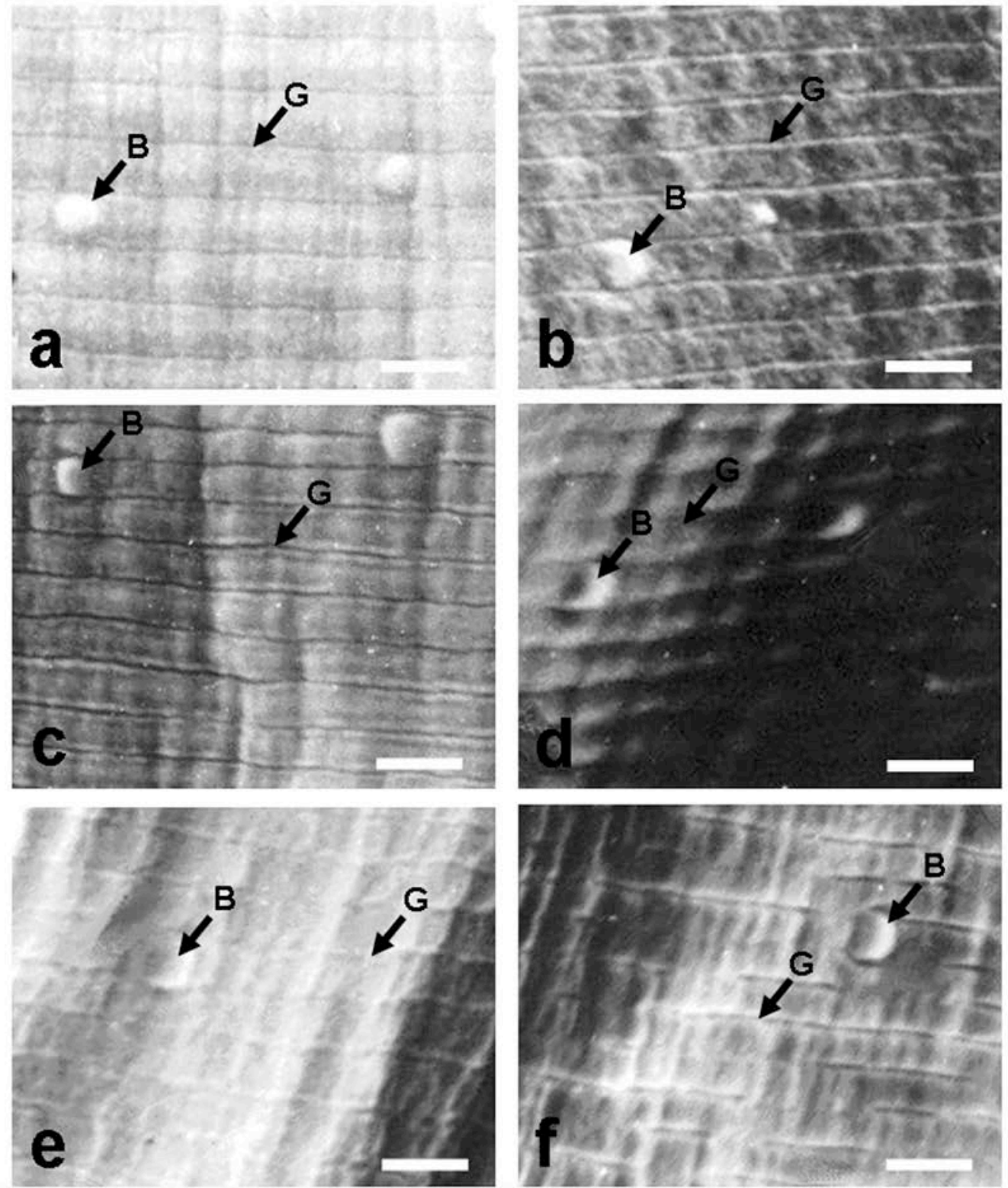

Fig. 1. Surface of adult female $S$. digitata:

Scanning electron microscopic studies on the surface of adult female (a, c, e) and male (b, d, f) S. digitata. Surface of Normal S. digitata (a and b) treated with $0.5 \%$ TX 100 for $5 \mathrm{~min}$ (c and d) treated with $0.5 \%$ TX 100 for $10 \mathrm{~min}$ (e and f) showing bosses (B) and grooves (G). Scale bar is $40 \mathrm{~nm}$. 
$\mathrm{X}-100$ and studied the changes which occurred on the surface of the parasite.

\section{Materials and methods}

\section{The parasites}

The parasite used for the study was $S$. digitata, a lymphatic filarial parasite found in the peritoneal cavity of the cattle.

\section{Collection of parasite}

The parasites were collected from the peritoneal cavity of freshly slaughtered cattle from the local abattoir. The worms were washed in Tyrode medium (composition w/v $\mathrm{NaCl} 0.8 \%, \mathrm{KCl} 0.02 \%, \mathrm{MgCl}_{2} 0.01 \%, \mathrm{CaCl}_{2} 0.02 \%$,

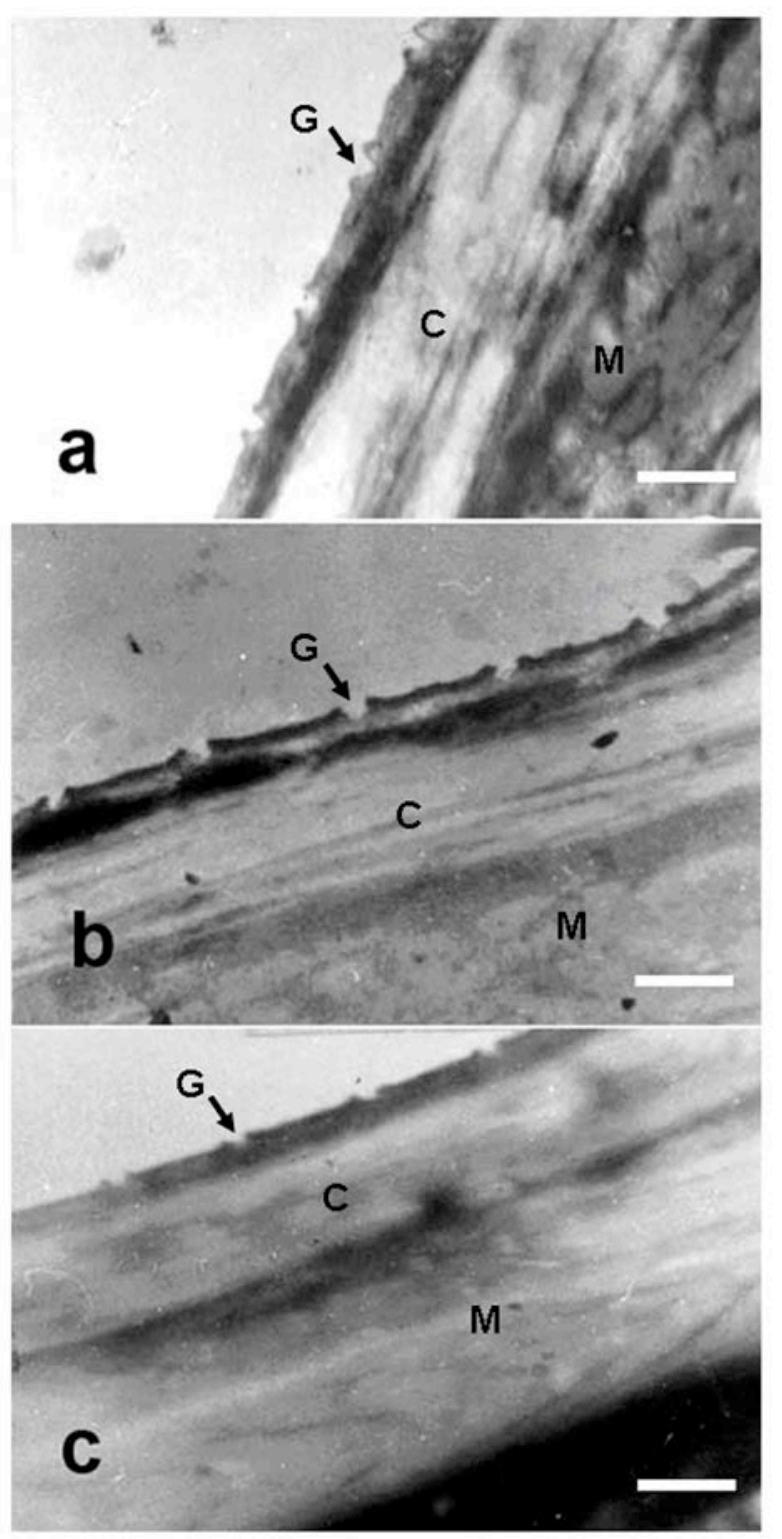

Fig. 2. Transverse section of body wall:

Transmission electron microscopic picture of $S$. digitata, Cross section of Normal S. digitata (a) treated with $0.5 \%$ TX 100 for 5 min (b) and treated with $0.5 \%$ TX 100 for $10 \mathrm{~min}$ (c) showing cuticle (C), bosses (B) and grooves (G). Scale bar is $60 \mathrm{~nm}$.
$\mathrm{NaHCO}_{3} \quad 0.015 \%, \mathrm{Na}_{2} \mathrm{HPO}_{4} \quad 0.05 \%$ and $\mathrm{pH}$ adjusted to 7.2) to remove host materials and maintained in the same medium at $37^{\circ} \mathrm{C}$ until use

Excretory secretory materials

Healthy adult worms were incubated in Tyrode medium at $37{ }^{\circ} \mathrm{C}(2 \mathrm{ml} /$ worm $/ \mathrm{hr})$. The medium was replaced every hour with fresh lot of medium. The medium so collected for four hours was filtered immediately to remove the released $\mathrm{mf}$, pooled and then saturated with ammonium sulphate under ice-cold condition to precipitate ES materials. The precipitated protein was centrifuged at $12000 \times$ $\mathrm{g}$ and dissolved in PBS. The protein was dialysed against PBS to remove ammonium sulphate, estimated the concentration (Lowry et al., 1951) and was stored at $-20^{\circ} \mathrm{C}$ until use.

\section{Treatment with Triton $X-100$}

The worms were incubated in Tyrode medium containing 0 $-7 \%$ Triton $\mathrm{X}-100(\mathrm{v} / \mathrm{v})$ at $37^{\circ} \mathrm{C}$ for 5 to 10 minutes. The ES was prepared from the medium as described above. The parasites were washed with Tyrode medium without Triton $\mathrm{X}-100$ was incubated at $37^{\circ} \mathrm{C}$ to assess the time required to recover from paralysis.

\section{Scanning electron microscopy}

The ultra structure of adult $S$. digitata with special reference to cuticular surface was studied by scanning electron microscopy (Fang et al., 1987). Healthy live adult male and female worms were grouped into three. One group was treated as normal and maintained in the same medium and the other groups were treated with $0.5 \%$ Triton X-100 in the same medium for 5 minutes and 10 minutes duration. About 20 worms from each group was washed with cold $0.1 \mathrm{M}$ sodium phosphate buffer of $\mathrm{pH} 7.2$ (SPB) and fixed in $3 \%$ glutaraldehyde in the same buffer at $0-4{ }^{\circ} \mathrm{C}$ for four hours. The worms were then washed in 10 changes of SPB and stained with $1 \%$ osmium tetroxide (was gift from Prof. Andrej Hasilik, Institute of Physiological Chemistry, Philipps-University Marburg, Marburg, Germany) in $0.1 \mathrm{M} \mathrm{SPB}$ at $25^{\circ} \mathrm{C}$ for 2 hours. The worms were washed for $12 \mathrm{hrs}$ with several changes of SPB. The parasites were then cut into $5 \mathrm{~mm}$ pieces with a razor, dehydrated with ascending concentration of acetone $(25 \%$, $50 \%, 75 \%$ and $100 \%$ ) for 10 minutes each at $0-4{ }^{\circ} \mathrm{C}$ and embedded on stubs. The materials on stubs were coated with gold and observed under JEOL JSM 35C scanning electron microscope.

\section{Transmission electron microscopy}

Healthy adult male and female worms were grouped into three. One group was treated as normal and maintained in the same medium. The other group was treated with $0.5 \%$ Triton X-100 in the same medium and maintained at $5 \mathrm{~min}$ and 10 min duration respectively. These were then washed in SPB, cut in to $0.5 \mathrm{~cm}$ long pieces, fixed in $2.5 \%$ glutaraldehyde in SPB at $4{ }^{\circ} \mathrm{C}$ for 4 hours. After fixing, the pieces were washed with SPB at $4{ }^{\circ} \mathrm{C}$ overnight. Samples 
were treated with $2 \%$ osmium tetroxide for 2 hours in the same buffer, washed for 12 hours with several changes of SPB and dehydrated with an ascending concentration series of acetone $(25 \%, 50 \%, 75 \%$, and $100 \%)$. Fully dehydrated samples were embedded in Spurr's epoxy resin. Thin section of the worms have been cut with an LKB Ultratome IV using a glass knife and, mounted on copper grids. The sections were stained with uranyl acetate and lead citrate and observed using a Carl Zeiss EM 109 electron microscope operated at an accelerating voltage of $80 \mathrm{kv}$.

\section{Results}

The estimation of protein showed a significant increase in the amount of protein in the medium in presence of Triton X-100 (Table 1). The worms were paralysed at the end of the experiment. When transferred to a Triton X-100 free medium the worms were recovered completely in the case of the lower concentration. However the paralysis was irreversible in the case of the higher concentration (Table 1).
The SEM on the surface (Fig. 1) showed that the surface of the parasite has transversely striated cuticle. Number of button like structures called bosses could be seen on the surface. More number of bosses was found on the posterior side than on the anterior side of the parasite. On treatment with Triton X-100, the striations appeared deep and bosses clearer. Increase in the time of incubation with Triton $\mathrm{X}$ 100 showed vertical wrinkling on the parasite wall. The SEM on the cross sections of parasite wall (Fig. 2) showed similar characteristics as the depth of grooves in the striations increased in response to the time of Triton X-100 treatment.

The TEM studies (Fig. 3) showed that the cuticle has annulations of uniform pattern. The Triton X-100 treatment altered the structure of annulations and increased the gap between striations which resulted in the formation of deep grooves. There were less electron dense layer on the annulations and more electron dense cloudy layer on the surface of annulations. When treated with Triton X-100, the outer layer on the annulations disappeared (Fig. $3 \mathrm{C}$ and D) and the depth of grooves deepened. Some hole like
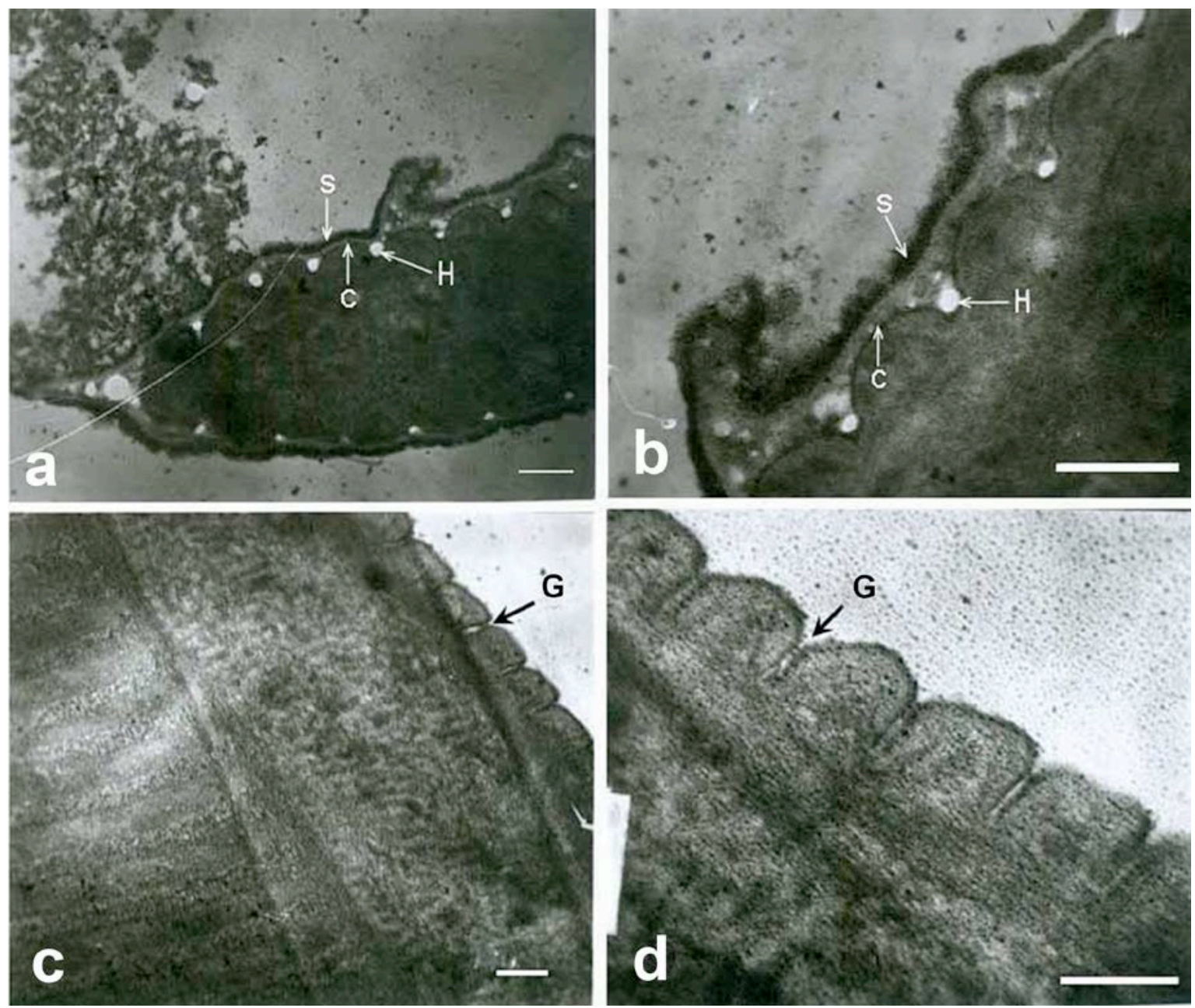

Fig. 3. Cross section of body wall:

Transmission electron microscopic picture of $S$. digitata showing annulations and outer layer. Electron dense outer layer aS and bS, inner layer aC and $\mathrm{bC}$, hole like structure $\mathrm{aH}$ and $\mathrm{bH}$, increase in the space between annulations $\mathrm{cG}$ and $\mathrm{dG}$. Scale bar is $60 \mathrm{~nm}$. 
structures found on the grooves of annulations also disappeared on treatment with Triton X-100.

\section{Discussion}

The study clearly showed that treatment with Triton X-100 enhanced the amount of ES protein released into the medium. The striations on the cuticle are actually the annulations of the cuticle. The results obtained showed that the structure of parasite wall is similar to the surface of $W$. bancrofti (Araujo, 1995; Oliveira-Menezes, 2007). The results support the use of $S$. digitata as a model organism for research in filariasis. The increase in gap between striations and the formation of deep grooves make the striations more clear. This may be due to washing out of materials present on the grooves or shrinkage of annulations due to Triton X-100 treatment.

The dose dependent increase in the release of protein may be due to solubilisation of the surface protein. The electron dense cloudy layer on the surface disappeared after treatment with Triton X-100. There may be a layer of materials washable with Triton X-100 or due to pealing off of a loosely held outer layer and exposure of the inner surface. The previous study suggests that most of the free-living and parasitic nematodes have these characteristics. It is the surface coat rather than the cuticle that displays dynamic properties thought to be involved in immune evasion by parasites (Blaxter et al., 1992). This may be a loose layer composed of molecules derived from parasite as well as adhered molecules of the host. Our study (Madathiparambil et al., 2009) as well as recent proteomic analysis of ES (Kwan-Lim et al., 1989; James et al., 2009) showed that a large amount of protein is secreted by the parasite. The ES also contains different kinds of enzymes which include proteases also which are crucial for the survival of pathogen (Pokharel et al., 2006) and other immunologically active molecules (John \& Raj RK, 1998; Muthian, 2006). In spite of the presence of all these molecules that can generate antibodies or other kind of immune responses (Bailey et al., 1995), the host system fails to recognize these molecules on the parasite (Bright \& Raj, 1994). The surface coat may be holding the secreted molecules in the surrounding environment for dealing with the possible reactions from the host. The findings in one sense supports the 'surface epitope hiding model' proposed earlier (Bright $\&$ Raj, 1994). The grooves and striations could function as suitable hiding places where the strategic molecules can remain like a soldier in a bunker. The mode of action of the anthelmintic drug Albendazole on the structure of the cuticle of Wuchereria bancrofti (Oliveira-Menezes, 2007) will be interesting in this context. Biochemical study apart from this morphological/physical nature of the wall and surface coat is needed to elucidate the hosting of the active secretory molecules by the surface coat and its immunological significance.

\section{Acknowledgements}

The authors thank Dr. P. Vijayachari, Director, Regional Medical Research Centre (ICMR) Port Blair, Andaman and Nicobar Islands, India and Dr. Annie John, Sree Chitra Tirunal Institute for Medical Sciences \& Technology, Poojapura, Thiruvananthapuram, India for their keen interest and support.

\section{References}

Araujo, A. C., Figueredo-Silva, J., Souto-Padrón, T., Dreyer, G., Norões, J., De SouZA, W. (1995): Scanning electron microscopy of adult Wuchereria bancrofti (Nematoda: Filarioidea). J. Parasitol., 81: 468 - 474

Bailey, J. W., Hightower, A. W, Eberhard, M. L., LAMMIE, P. J. (1995): Acquisition and expression of humoral reactivity to antigens of infective stages of filarial larvae. Parasite. Immunol., 17: 617 - 623

Blaxter, M. L., Page, A. P., Rudin, W., Maizels, R. M. (1992): Nematode surface coats: actively evading immunity. Parasitol. Today., 8: $243-247$

BRIGHT, J. J., RAJ, R. K. (1991): Isolation and analysis of surface antigens of filarial nematode Setaria digitata. Indian. J. Exp. Biol., 29: 725 - 729

BRIGHT, J. J., RAJ, R. K. (1992): Antigenic analysis of purified surface antigens of filarial nematode Setaria digitata. Indian. J. Exp. Biol., 30: 362 - 366

BRIGHT, J. J., RAJ, R. K. (1994): Ontogenetic transformation of surface epitope expression, an adaptive immunoevasive strategy of filarial parasites. Indian. J. Exp. Biol., 32: $49-54$

DeCRUSE, S. W., Raj, R. K. (1990): Histological studies on female Setaria digitata (von Linstow 1906), a filaria of bovine (Bos indicus). Proceedings of Indian Academy of Science (Animal Science) 99(2): $103-111$

DEVI, C. M., RAJ, R. K. (1996): Histological changes in the spleen of $\mathrm{BALB} / \mathrm{C}$ mice caused by excretory-secretory protein(s) of Setaria digitata (von Linstow). Indian. J. Exp. Biol., 34: 32 - 36

DHAS, K. P., RAJ, R. K. (1995): Epitope specific monoclonal antibodies from heterologous antigen for immunodiagnosis of filariasis. Indian. J. Med. Res., 101: 183 - 189 FANG, T. K., DONALDSON, R. P., VigiL, E. L. (1987): Electron transport in purified glyoxysomal membranes from castor bean endosperm. Planta., 172: 1 - 13

Hawking, F. (1978): Diethylcarbamazine WHO/ONCHO/78.142.1.

James, P. H., John, R. G., Maizels, R. M. (2009): Helminth immunoregulation: The role of parasite secreted proteins in modulating host immunity. Mol. Biochem. Parasitol., 167: 1 - 11

JOHN, L., RAJ, R. K. (1998): Immune response of electroeluted detergent soluble $29 \mathrm{kDa}$ antigen from Setaria digitata (von Linstow). Indian. J. Exp. Biol., 36: 862 - 866 
KAGEI, N. (1960a): Morphological studies on thread worm, Filarioidea. Report 1. Morphological structure of Setaria cervi. Acta. Med. Univ. Kagoshima., 2: $142-149$

KAGEI, N. (1960b): Morphological studies on thread worm, Filarioidea. Report 2. On the microstructure of body wail and uterus of adult Setaria cervi. Acta. Med. Univ. Kagoshima ., 2: $150-157$

KAGEI, N. (1963): Morphological studies on thread worm, Filarioidea. Report 5. On the microstructure of male of Litomosoides carinii (Travassos, 1919), Filaria of cotton rat. Acta. Med. Univ. Kagoshima., 5: 43 - 53

Kwan-Lim, G. E., Gregory, W. F., Selkirk, M. E., PARTONO, F., MAIZELS, R. M. (1989): Secreted antigens of filarial nematodes: a survey and characterization of in vitro excreted/secreted products of adult Brugia malayi. Parasite. Immunol., 11: $629-654$

Madathiparambil, M. G., Kaleysa, K. N., Raghavan, K. (2009): A diagnostically useful $200-\mathrm{kDa}$ protein is secreted through the surface pores of the filarial parasite Setaria digitata. Parasitol. Res., 105: 1099 - 1104

MURUGAN A., KALEYSARAJ R. (1991): In vitro release of biologically active materials from the bovine filarial parasite Setaria digitata. Indian. J. Exp. Biol., 29: 1047 - 1050 Muthian, G., Pradeep, C. G., SargapradeeP, K., KaleysaraJ, R., Bright, J. J. (2006): Setaria digitata secreted filarial lipids modulate IL-12 signaling through JAK-STAT pathway leading to the development of Th1 response. Exp. Parasitol., 114: 193 - 203

OliveIRA-MENEZES, A., Lins, R., NORÕEs, J., DreYER, G., LANFREDI, R. M. (2007): Comparative analysis of a chemotherapy effect on the cuticular surface of Wuchereria bancrofti adult worms in vivo. Parasitol. Res., 101: 1311 1317

Pokharel, D. R., Rai, R., NANDAKUMar, K. K., RedDy, M. V., RATHAUR, S. (2006): Vaccination with Setaria cervi $175 \mathrm{kDa}$ collagenase induces high level of protection against Brugia malayi infection in jirds. Vaccine., 24: 6208 $-6215$

SHENG, Y. L. (1958): The differentiation of Setaria cervi and Setaria digitata, the two species commonly found in ruminants in Asia (Demonstration). Trans. R. Soc. Trop. Med. Hyg., 52: 11

SHENG, Y.L. (1959): A revision of the nematode genous Setaria Viborg, 1795, its hostparasite relationship, speciation and evolution. J. Helminthol., 33:1 - 98

SugunAN, V. S., RAJ, R. K. (1990): Excretory/secretory antigens from a bovine filarial parasite cross react with human antifilarial antibodies. Indian. J. Exp. Biol., 28: $1124-1127$ 